\title{
Effects of Customer Knowledge Management on Marketing Management and Results: Case Study in Business Companies, FARS
}

\section{Seyedmohammad Hosseinifard,}

Seyedmohammad Hosseinifard, M.Sc. in International Business Management(Full-time MBA), Furtwangen University, Germany

\section{Fateme Tohidi,}

M.Sc. in Accounting, Islamic Yazd Azad University, Yazd Branch, Iran

\section{Hamidreza Abootalebi Jahromi,}

MBA: Financial, Management Department, Apadana Institute of Higher Education, Shiraz, Iran

Navid Abootalebi Jahromi,

Business and Management Department,

Yorkville University, Toronto, Canada

Nakisa Adib,

Engineering Department, Islamic Azad University of Shiraz, Iran

\section{Abdolhossein Ayoubi,}

M.Sc. of Biomedical Information Technology, Biomedical Engineering

Department, Amirkabir University of Technology, Tehran, Iran

Doi:10.19044/esj.2020.v16n16p244 URL:http://dx.doi.org/10.19044/esj.2020.v16n16p244

\begin{abstract}
The purpose of the present study was to investigate the impact of customer knowledge management on marketing management and marketing results in Fars business companies. Statistical population of the present research includes 1135 employees and managers of Fars business companies which with using formula, 290 individuals were questioned with random sampling. To collect data, standard questionnaires including Vorhies \& Morgan's (2005) marketing questionnaire, Ling-Yee's (2005) marketing management questionnaire, Alegri's (2011) knowledge management questionnaire were used. In order to confirm their reliability, their coefficient Cronbach's alphas are respectively $0.82,0.79$ and 0.88 . For data analysis, inferential statistics, Pearson correlation test, Single variable regression, Path analysis and SPSS software version 22 were used. The results showed that there is a positive and meaningful relationship between customer knowledge management, marketing results (efficiency) and marketing management. Also,
\end{abstract}


knowledge management had a positive and significant impact on marketing management and marketing results. Moreover, proposed conceptual model is supported.

Keywords: Knowledge management; marketing management; marketing results

\section{Introduction}

Dominant markets in every country are considered as a symbol of their economic, social and political situation, because the markets and their results identify behaviors and relationships that are prevailing in the economy of that society. On the other hand, with the arrival of the twenty-first century, global competitive circumstances and context of human life has changed so fast. The depth of these changes not only at the beginning of the twentieth century, but also even compared to two decades ago, is highly tangible and visible. Paying attention to human resources as well as market changes under the effects of organization's human resources 'capabilities and their managers' power which lead to market efficiency or improve marketing results, can be their major reasons. It seems that in its light, globalization can be set free from the limitations of the former boundaries. As a result of this phenomenon, human activity and the processes of production and consumption will be organized more freely under the effects of its knowledge and management.

In this regard, the results of marketing and marketing management perpetuated their role in a more specialized and complex way, in success or failure of the production and supply of goods to market in businesses and commercial companies and became much more important. Marketing, with a strong presence of knowledge management in computer-based information systems and use of advanced communication technologies and development of mass media, has found a dynamic and strategic process outside of its traditional and static framework. Growth of market due to customer knowledge management and its impact on marketing management in recent years should be considered not only as an effective promotion in market development history but also as reaching to higher efficiency and results in the market.

The purpose of the present study was to evaluate the effect of customer knowledge management on marketing management and marketing results in active businesses and commercial companies in Fars State, Iran. This study examines the effects of theoretical foundations of variables of marketing results as dependent variable, marketing management as independent variable and customer knowledge management as a mediator variable. 


\section{Review of Literature}

\section{Marketing Results (Efficiency) and Marketing Management}

A market based on its information systems is effective and has a positive result when prices reaction takes place at a time that all components observe those signs of knowledge management and information systems. In other words, we see the price changes when there is widespread awareness of knowledge and information. In a more comprehensive way, market results (or market efficiency) measures the degree of companies' achievements to their business goals in the markets. This measurement includes the measurement of market share, revenue, and finding and keeping the customer (Fidel et al., 2015).

Marketing Management is the process of planning and implementing the concept, pricing, advertising, promotion and distribution of ideas, goods and services in order to carry out some transactions which leads to individual and organizational goals. Achieving this goal depends on how we calculate and analyze regular and specific needs, demands and market mediators as a basis for decisions about products, pricing, communication and distribution (Kotler, 2003).

According to Agravel (1982), in process of marketing management, the results of the market can be observe as market reactions such as sale of market share and similar ways with strategic marketing objectives and policies of marketing (product development, pricing, distribution channels and control organization). In this issue, the investigations carried out by Fidel et al. (2015), Azizi et al. (2010), Ling-Yee (2011) and Arachandran et al. (2005) showed positive and meaningful relationship between marketing results and marketing management. Therefore, in this study, considering the likely impact of marketing management on marketing results, the Following hypothesis will be examined:

H0: Marketing Management has positive impact on marketing results in Fars business companies.

\section{Knowledge Management and Marketing Management}

Marketing is an attempt to reduce internal and external risks. With the use of contingency procedures, it will evaluate the situations and guarantee organizations' reaction towards them. Marketing management is the exchange between groups in order to reach an agreement on the mutual interests (Kotler \& Keller, 2012).

On the other hand, knowledge as the major source of organizational efficiency has a paramount importance. The main objective of knowledge management is to create and organize an environment in which people develop their knowledge, share it with each other, mix their knowledge with others and finally apply it. In fact, knowledge management is strategies and processes 
that are able to produce and process knowledge in order to develop and meet the expectations of customers and users in the entire organization. Knowledge management is a wide process which pays close attention to identify, to organize, to transfer and proper use of information and experiences inside the organization. Today, knowledge is the most important asset of every organization. Hence, knowledge management is a challenge to discover the individual knowledge and turn it into a data so that it can be stored in databases. Then, exchange it with others and use it in everyday business processes (Alborzi, 2004).

Customer knowledge management involves identifying and determining the intellectual capitals in an organization, producing new knowledge to maintain its competitive advantage, providing access to large amounts of information and sharing the best performance. Technology enables all of the above achievements (Barclay \& Murray, 2006).

We can also note that customer knowledge management dimensions shapes with the application of knowledge. These dimensions include knowledge management systems, local capabilities and business secrets. Performing these knowledge management customers' components allows companies to carry out several activities. Create a customer-center knowledge management affects mostly the dynamic capabilities in dimensions of customer knowledge management (Alavi \& Leidner, 2001).

According to above theoretical foundations, it seems that knowledge management can have a direct and positive impact on marketing management and also can increase the impact of marketing management on marketing results.

H0: Marketing management has a significant impact on marketing results with the mediating role of knowledge management in Fars businesses companies.

\section{Marketing Results and Customer Knowledge Management}

Knowledge management should be viewed as integrated management plans which focuses on strategic goals, moves around business processes and gets help from technology (Nohr, 2002).

According to Nohr (2002), Knowledge management is an effort for providing information in a proper time and convenient location. Knowledge management can be investigated at two levels: Strategic (to determine the objectives of the organization) and operational (to Fulfill and implement of objectives and various plans of knowledge management: identification of knowledge, explicit knowledge, knowledge acquisition, knowledge generation, knowledge distribution, knowledge utilization and knowledge evaluation). 
Paying attention to customer knowledge management, market orientation and consequently to customer orientation can lead to two major consequences: Behavioral and functional outcomes. Behavioral outcomes include creating a spirit of collective work and increase employee's commitment to the organization. Functional outcomes include: Maximizing the results of the function of increasing sales, increasing market share (market results) and increasing customer and client's satisfaction ( Shoham et al. , 2008).

In fact, use of customer knowledge management in organizations leads to higher performance, productivity, efficiency and effectiveness, higher satisfaction and hope between employees, clients and customers (Vijayan , 2002). In addition to the theoretical foundations that show relationship between customer knowledge management and marketing results, in this regard, studies such as Fidel et al. (2015), Zack et al. (2009) and Massey et al. (2002), reported a positive relationship between knowledge management, marketing results, performance and organizational performance. Moreover, Economists have reported a positive relationship between knowledge management and financial results such as sales, market share and profitability (Huang \& Shih, (2009); Chadam \& Pastuszak (2005).

Therefore, according to the above discussion, the following hypothesis will be investigated:

H0: Marketing Management has positive impact on marketing results in Fars business companies.

According to previous discussions and theoretical framework, Figure 1 shows the conceptual model used in this study.

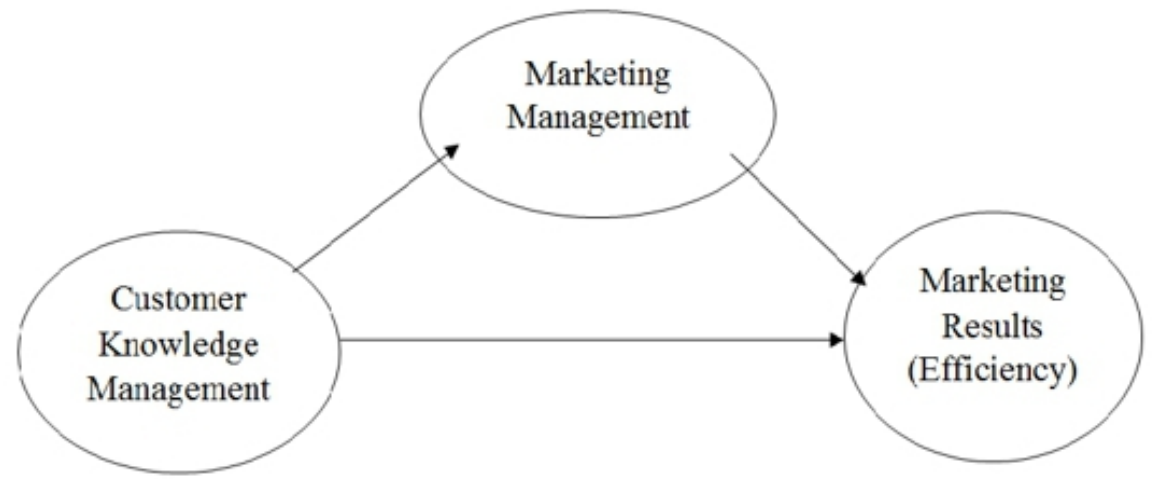

Figure 1. Proposed Conceptual Model

\section{Materials and Methods}

The present study in terms of purpose is applied one. Data collection is descriptive - survey and in terms of implementation is a field study. 


\section{Data Collection}

For measuring marketing results, Morris and Morgan's (2005) scale and for assessment of marketing management, Ling-Yee's (2005) marketing management were used. Aforementioned questionnaires are standard and their validity and reliability are confirmed. Also, in Fidel et al. (2015)'s study validity and reliability of these questionnaires are confirmed. Moreover, in this study validity and reliability of them are confirmed with professors and professionals' consultation in the field. In order to confirm the reliability, with using Cronbach's alpha in SPSS software version 22, in a pre-test with population of 30 individual, questionnaires were distributed and their Cronbach's alpha were calculated. Respectively for marketing results, marketing management and customer knowledge management, their coefficient Cronbach's alphas are 0.82, 0.79 and 0.88 and because they are higher than 0.7 their reliability is approved.

\section{Population, Statistical Sample and Sampling Methods}

Statistical population of the present research includes 1135 employees and managers of Fars business companies. To calculate the Statistical sample, the following formula can be used to determine the sample size (Sarmad et al., 2007):

$$
n=\frac{n_{\mathrm{o}}}{1+\frac{n_{\mathrm{o}}}{N}}
$$

$\mathrm{N}=1135$ (Sample Size)

$$
n_{0}=\frac{Z^{2} a / 2 p q}{E^{2}}
$$

The above formula is used when the variance is unknown and it is assumed that $\mathrm{P}$ is the proportion of people in each area and it is equal to 0.5 (highest possible value). The error rate was considered 0.05 , therefore:

$$
n_{0}=\frac{(1.96)^{2}(0.5)(0.5)}{(0.05)^{2}}=384.16
$$

As a result, the sample size is as follows:

$$
n=\frac{384.16}{1+\frac{384.16}{150}}=107.91 \cong 289
$$

Thus, the sample size was considered 290. Also, in this research random sampling was used. 


\section{Findings and Results}

Pearson correlation analysis was used before using path analysis for better understanding of relationship between variables that its results, along with mean and standard deviation of variables are shown in Table 1.

Table 1. Correlation Matrix between the Components of Customer Knowledge Management, Marketing Management and Marketing Results

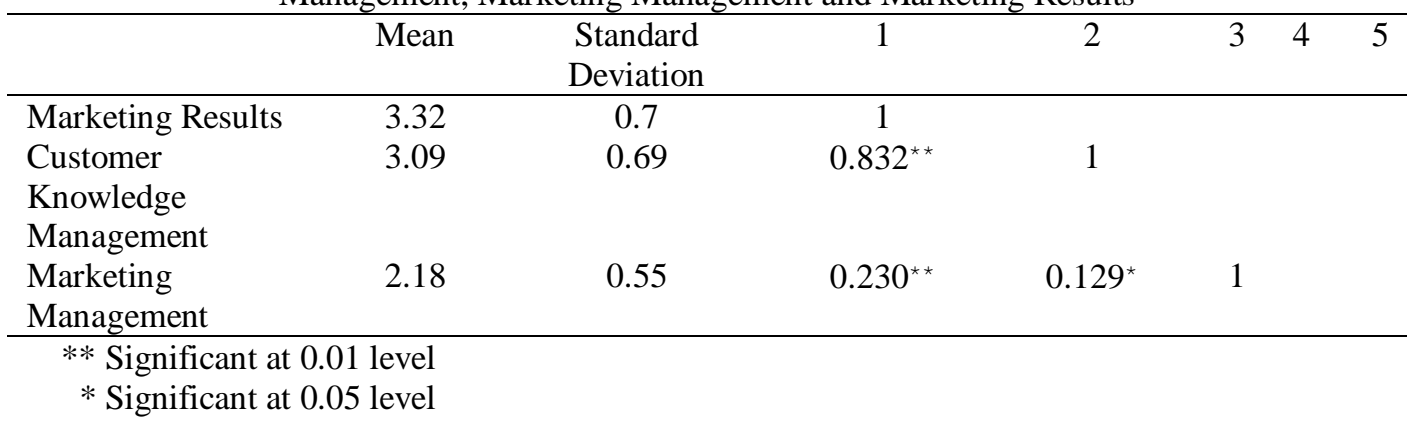

According to Table 1, marketing results mean is higher than other variables. Besides, based on the correlation coefficient matrix, it can be concluded that between customer knowledge management, marketing results, and marketing management variables in a significant level of $p<0.01$ and between marketing management and market results in a significant level of $\mathrm{p}<0.05$ there is a significant and meaningful relationship.

In this study, to check the conceptual model, path analysis technique was used. Path analysis technique is based on a set of regression analysis and relationship between independent and dependent variables. Path diagram uses for visual expression of the relationship between variables in path analysis (Kalantari, 2006). Since market results (efficiency) was the dependent variable, for analysis in this way and calculating the direct and indirect effects of the independent variables of customer knowledge management and marketing management on dependent variables of marketing results (efficiency), First, we should draw path diagram which represent direct and indirect relationships and effects of each variable on other variables (Figure 1). After path coefficients were obtained for all split directions, direct and indirect effects of independent variables on dependent variable of market results are achievable through combination of above charts. Path coefficients for all paths are presented in Figure 2. 


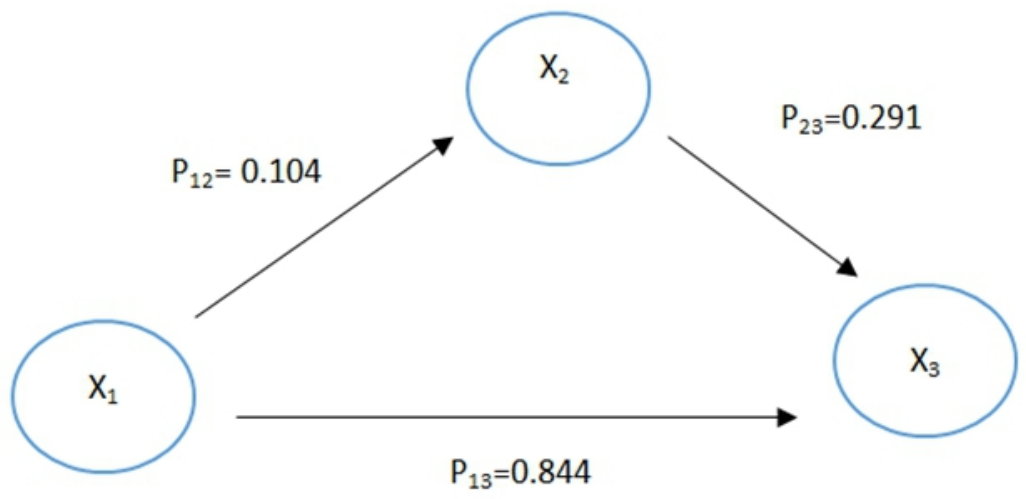

Figure 2. Path Analysis Chart with Beta Coefficients

In Figure 2, X1, X2 and X3 are respectively customer knowledge management, marketing management, market results. P12, P13 and P23 shows respectively the relationship between customer knowledge management and marketing management, relationship between customer knowledge management and marketing results and relationship between marketing management and marketing results.

After obtaining the beta coefficients, the direct and indirect effects of each independent variable on the dependent variable can be calculated. Since the beta coefficients use in path analysis diagram and these coefficients are standardized, therefore, we can compare the effects of different variables with each other and determine the most effective one. To obtain total effects, we should add direct and indirect effects with each other. Hence, we can realize the importance of each path through comparison of beta coefficients for different paths.

Table 2 shows the direct and indirect effects of marketing management and customer knowledge management on marketing results.

According to information obtained from regression analysis:

- Direct effect of marketing management on marketing results was equal to 0.291 and significant in confidence level of 0.01 ,

- Direct effect of customer knowledge management on marketing results was equal to 0.844 and significant in confidence level of 0.01

- Direct effect of customer knowledge management on marketing management was equal to 0.104 and significant in confidence level of 0.01

- Indirect effect of marketing management on marketing results through marketing management was equal to 0.874 . 
Table 2. Calculation of Direct and Indirect Effects of Customer Knowledge Management on Marketing Results

\begin{tabular}{ccc}
\hline Type of Effect & Path & $\begin{array}{c}\text { Amount of Effect Based on } \\
\text { Beta Coefficients }\end{array}$ \\
\hline Direct effect & $\mathrm{X}_{1} \rightarrow \mathrm{X}_{3}$ & .0844 \\
Direct effect & $\mathrm{X}_{1} \rightarrow \mathrm{X}_{2}$ & 0.104 \\
Indirect Effect & $\mathrm{X}_{1} \rightarrow \mathrm{X}_{2} \rightarrow \mathrm{X}_{3}$ & $(0.104) \times(0.291)=0.03$ \\
Total effects of Direct and Indirect & 0.978 \\
\hline
\end{tabular}

\section{Discussion and Conclusion}

According to the results of data analysis and hypothesis testing, the conclusion of each hypothesis can be stated as follows:

Marketing management has positive and direct impact on marketing results in Fars business companies and also with regard to the mediating role of customer knowledge management, this relationship becomes stronger.

Moreover, customer knowledge management has a direct and positive impact on marketing results (efficiency) and increases it. In fact, the more customer knowledge management we use, the higher results and performance we get. This result is quite predictable, because, all the marketing strategies and tactics are based on implicit and explicit beliefs of consumer behavior (i.e. customer knowledge management). Probability of successful decisions which is made based on correct assumptions, theories and proven studies are more than decisions that are made only on the basis of intuition and implicit beliefs. Accordingly, knowledge of consumer behavior can be a significant competitive advantage and reduce the wrong decisions (Rousta, 2007).

These factors due to customer knowledge management are the most important factor and positively improve the marketing results. Apart from development of effective knowledge management systems, organizations need cultural education to generate stimulating and innovative ideas in marketing management and improve their customer knowledge management (Fidel et al., 2015). The results present several concepts for business managers and prove the need to implement a consistent customer knowledge management in commercial and businesses companies. Companies that exploit the policies and procedures of customer knowledge management and marketing management adequately will identify the market opportunities better that their competitors with more chance of success and will achieve better market results. A moderate level of marketing management emphasizes the need for effective implementation of customer knowledge management in companies (i.e. market research activities). Also, main factors of customer knowledge management are inputs of marketing management (Due to the impact on customer knowledge management and marketing results). By strengthening and paying more attention to these main input factors, 
companies are able to improve market results and thus are able to improve their efficiency and maintain their competitive advantage.

Thus, according to significant and positive impact of customer knowledge management on marketing management and market results, it is recommended that commercial and business companies in order to achieve higher performance, identify various dimensions of the need for knowledge in different aspects of their activities and import knowledge management in all areas of their activities with a coherent and consistent planning. Therefore, with more control over their marketing management, they can win this tough competition.

Also, since the concept of knowledge management without IT knowledge has very limited capacity, the most value of technology in knowledge management is increasing and accelerating the access to knowledge as well as transferring it between employees, customers and client. Information technology allows the extraction of knowledge from its owner mind. Then, with technology we can put that knowledge into neat and organized framework and transfer it to other company's members, business partners and even global partners to guarantee reaching market results.

\section{References:}

1. Alavi, M., \& Leidner, D, 2001. Knowledge management and knowledge management systems: Conceptual foundations and research issues. MIS Quarterly, 25, 107-133.

2. Alegre, J., Sengupta, K., \& Lapiedra, R., 2011. Knowledge management and the innovation performance in a high-tech SMEs industry. International Small Business Journal, 31(4), 454-470.

3. Albrozi, S., 2015. October 8. Knowledge management. Retrieved from www.hamshahrionline.ir

4. Arachandran, S., Sharma, S., Kaufman, P., \& Raman, P., 2005. The role of relational information processes and technology use in customer relationship management. Journal of Marketing, 69, 177-192.

5. Azizi, S., Makizade, V. \& Bastamt, B. 2015, October 10 .A marketing capability based export performance model for Iran software market. Retrieved from https://jitm.ut.ac.ir/article_22172_0.html

6. Barclay, R.O, Murray, P.C., 2006. What is knowledge management? knowledge parxi, 10.pp:49-60.

7. Chadam, J., \& Pastuszak, Z. 2005. Marketing aspects of knowledgebased management in groups of companies, case of Poland. Industrial Management \& Data Systems, 105(4), 459-475. 
8. Fidel, Pilar , Schlesinger, Walesska, Amparo Cervera. 2015. Collaborating to innovate: effects on customer knowledge management and performance. Journal of Business Research.

9. Huang, P., \& Shih, L. 2009. Effective environmental management through environmental knowledge management. International Journal of Environmental Science and Technology, 6(1), 35-50.

10. Kalantari, K. 2006. Processing and analysis of data on socio-economic research using SPSS software. Tehran: Sharif press.

11. Kotler, P. \& Keller, K. 2012. Marketing Management. 14th editions. Prentice Hall; February 18.

12. Katler, P. 2003. Marketing insights from a to z: 80 concepts every manager needs to know. New Jersey: Wily press.

13. Li, Ling-Yee, 2011. Marketing metrics' usage: Its predictors and implications for customer relationship management. Industrial Marketing Management. 40, 139-148.

14. Massey, A., Montoya-Weiss, M., \& O'Driscoll, T. 2002. Knowledge management in pursuit of performance: Insights from Nortel Networks. MIS Quarterly, 26(3), 269-289.

15. Nohr, H. 2000, Informationsqualitaetals Instrument des Wissensmanagments, Arbeitspapier Wissensmanagement 6/2000.

16. Nohr, H. 2002. Strategies - und Geschftsprozessorientiertes Wissens management, Hochschule der Mediem , Stuttgart. Holger, N. 2000. Wissen und wissen prozesse stuttgart nohr visualisieren. Arbeitspaper Nr.1-2000-www.hbl.

17. Rousta, A., Ebrahimi, A. \& Davar V. 2006. Marketing management. Tehran: Samt Press Sarmad, Z., Bazargan, A. \& Hejazi, E. 2008. Research methods in behavioral science. Tehran: Agah

18. Shoham A., Brencic M. M., Virant V., Ruvio, A. 2008. International standardization of channel management and its behavioral and performance outcomes. Journal of International Marketing; 16(2): 120-151.

19. Vijayan S., 2002. Intelligent Support Systems Technology: Knowledge management; IRM PRESS.

20. Vorhies, D., \& Morgan, N. 2005. Benchmarking marketing capabilities for sustained competitive advantage. Journal of Marketing, 69(1), 80-94.

21. Zack, M., McKeen, J., \& Singh, S. 2009. Knowledge management and organizational performance: An exploratory analysis. Journal of Knowledge Management, 13(6), 392-409. 